\title{
Patient Beliefs Predict Response to Paroxetine Among Primary Care Patients with Dysthymia and Minor Depression
}

\author{
Mark D. Sullivan, MD, PhD; Wayne J. Katon, MD; Joan E. Russo, PhD; \\ Ellen Frank, PhD; James E. Barrett, MD; Thomas E. Oxman, MD; and \\ John W. Williams, Jr, MD
}

Background: Dysthymia and minor depression are common problems in primary care, but it is not known how patient health beliefs shape response to antidepressant treatment of these less severe forms of depression.

Methods: Three hundred thirty-three primary care patients with dysthymia or minor depression received at least 4 weeks of paroxetine or placebo in a multicenter, randomized controlled 11-week trial. Patient health beliefs and other characteristics were examined as predictors of treatment adherence and depression remission.

Results: Patient beliefs were not predictive of adherence to paroxetine or placebo. Patients with less endorsement of biological beliefs about their condition (odds ratio $[\mathrm{OR}]=3.40)$, higher perceived general health $(\mathrm{OR}=3.38)$, meeting criteria for dysthymia $(\mathrm{OR}=2.37)$, and age younger than 60 years $(O R=2.68)$ were more likely to achieve remission on paroxetine. Patient beliefs did not predict remission on placebo. Those with lower severity of depression symptoms at baseline $(\mathrm{OR}=2.70)$ and women $(O R=2.18)$ were most likely to achieve remission on placebo.

Conclusions: Our results suggest that patients with dysthymia or minor depression are more likely to respond to antidepressant medication if they do not see their depression as a biological illness and see themselves as generally healthy. It is clearly not necessary for patients to believe that their dysthymia or minor depression is biological to respond to antidepressant medication. ( $\mathrm{J}$ Am Board Fam Pract 2003;16:22-31.)

Multiple epidemiologic studies of primary care populations have documented that depressive symptoms less severe than major depression are associated with impaired functioning ${ }^{1}$ and increased health care utilization. $^{2}$ These forms of depression appear to share the same demographic, social, and physical health risk factors as major depression. ${ }^{3}$ The role of physician and patient beliefs in the treatment of major depression has been

Submitted 4 April 2002.

From the Department of Psychiatry (MDS, WJK, JER), University of Washington, Seattle, the Western Psychiatric Institute (EF), University of Pittsburgh, the Department of Community and Family Health (JEB), and the Department of Psychiatry (TEO), Dartmouth Medical School, Hanover, $\mathrm{NH}$, and the Center for Health Services Research in Primary Care (JWW), HSR\&D, Department of Veterans Affairs Medical Center and Duke University Medical Center, Durham, NC Address reprint requests to Mark D. Sullivan, MD, PhD, Psychiatry and Behavioral Sciences, Box 356560 , University of Washington, Seattle, WA 98195.

This research was supported by grants from the John A. Hartford Foundation and the John D. and Catherine T. MacArthur Foundation. examined. Primary care physician beliefs about the burden and discomfort associated with diagnosing and treating depression, as well as their self-efficacy in diagnosing and treating depression, were significantly related to practitioner perceptions of depression as an important and frequent primary care problem. ${ }^{4}$ Depressed patients tend to endorse biological explanations of the causes of depression to a greater extent than clinical psychologists. In contrast, clinical psychologists assign a more important causal role to unconscious processes and childhood vulnerability factors than do either depressed patients or nondepressed lay controls. ${ }^{5}$ The role of patient beliefs in the care of minor depression and dysthymia has not been studied.

Dysthymia requires 2 years of depressive symptoms and occurs in approximately $5 \%$ of primary care patients. ${ }^{6}$ Most patients with dysthymia have multiple unexplained physical symptoms, such as headaches and fatigue. ${ }^{7}$ They often experience major depressive episodes with high rates of disability and relapse after recovery from the major depres- 
sive episode. ${ }^{8}$ Minor depression is less well characterized. ${ }^{9}$ Although initially defined in the 1970 s as part of the Research Diagnostic Criteria, it currently is still listed in the appendix of Diagnostic and Statistical Manual of Mental Disorders (4th ed) (DSM-IV) as a diagnosis under study. There is still lack of agreement concerning definitions and prevalence rates. ${ }^{10}$ Nevertheless, there is strong evidence from community ${ }^{11}$ and clinical ${ }^{12}$ samples that minor depression is associated with considerable disability. Most trials of treatment of minor depression have been in selected nonrepresentative populations and have not been well controlled. ${ }^{13,14}$

We recently published reports of the Treatment Effectiveness Project, a large, primary care-based, multicenter, randomized controlled trial comparing paroxetine, problem-solving therapy, and placebo in patients with minor depression or dysthymia. Paroxetine showed moderate benefit compared with placebo for depressive symptoms and mental health function in elderly patients with dysthymia and in elderly patients with minor depression who had more severe functional impairment. ${ }^{15}$ In younger patients, paroxetine and problem-solving therapy improved remission rates in patients with dysthymia compared with placebo. These active treatments did no better than placebo in the younger patients with minor depression. ${ }^{16}$

Patients with depression diagnosed in the primary care setting are more likely to receive antidepressants than psychotherapy. It would therefore be useful to know which beliefs of primary care patients with less severe forms of depression are predictive of adherence and remission when the depression is treated with antidepressant treatment or placebo. We therefore examined the role of patient beliefs in the context of other relevant patient characteristics to determine whether they helped predict response to antidepressants or placebo. The placebo group was included as a comparison group to determine whether predictive beliefs were specific to active treatment. We hypothesized that greater endorsement of a biological model of depression would be associated with greater adherence and remission on both paroxetine and placebo.

\section{Methods \\ Subjects}

The details of the study design have been described elsewhere. ${ }^{16}$ In summary, primary care patients aged 18 or older were recruited from patients currently enrolled in primary care practices (family medicine or general internal medicine) in four communities (Lebanon, NH; Pittsburgh, Pa; San Antonio, Tex; and Seattle, Wash). The Seattle and Lebanon sites enrolled patients in both a younger age cohort (18-59 years) and an older age cohort ( $\geq 60$ years), whereas San Antonio and Pittsburgh enrolled only the older age cohort. To be included, a participant needed to have three or four of the DSM-IV symptoms of depression on the Prime-MD major depression module, ${ }^{13}$ one of which was depressed mood or anhedonia as assessed by clinical interview, and to have a 17 -item Hamilton Rating Scale for Depression (HAM-D) score of 10 or greater. ${ }^{14}$ Patients with dysthymia were required to have experienced symptoms for at least 2 years. Patients were excluded if, within the previous 6 months, they had major depression, active substance abuse, uncomplicated bereavement, parasuicidal behavior, or antisocial personality. $\mathrm{Pa}-$ tients currently taking psychotropic drugs, seeing a psychotherapist, or suffering from a cognitive impairment (Mini Mental State Examination $\leq 23)^{15}$ or a terminal illness (less than 6 months to live) were also excluded.

\section{Procedures}

Each site used a variety of methods to educate participating primary care providers about referral. Brief depression-screening instruments were also used at some sites to select potential participants. Participants thus were defined in a primary care practice setting as potentially having either dysthymia or minor depression and were referred for a research evaluation. A two-phase evaluation took place within 1 week of patient selection. The initial phase was a semistructured clinical interview to determine eligibility. ${ }^{13}$ For patients meeting criteria, a complete description of the study was provided, and written informed consent approved by the local institutional review board was obtained. Those who agreed to participate were then administered additional baseline measures and randomized to one of the three treatment arms. Participants in all three arms were offered six subsequent treatment visits at 1, 2, 4, 6, 8, and 10 (for PSTPC) ${ }^{16,17}$ or 11 (for paroxetine and placebo) weeks. Only those participants randomized to paroxetine or placebo are included in the present analysis. 


\section{Measures}

Beliefs

Participants' beliefs about the causes and nature of their depression were assessed before randomization with the 20-item Patient Attitudes and Beliefs (PAB) Scale, originally developed for the National Institute of Mental Health Collaborative Study of Depression Treatments. ${ }^{17}$ The PAB was designed to assess patients' beliefs about the cause of their depression along three dimensions: biological, cognitive, and external. Biological items assess the extent to which patients believe the cause of their depression is primarily related to neurotransmitter or genetic factors. Cognitive items assess the extent to which patients believe that their depression results from the ways that they think about themselves and the world. External items assess the extent to which patients believe that their depression results from events outside themselves, such as losses or conflicts. Scores from each scale were summed and standardized into three scale scores in which higher scores indicate greater endorsement of those beliefs. A factor analysis of the PAB data obtained on our sample supported a two-factor solution, with one factor comprising the biological beliefs scale and the other factor comprising the cognitive and external scales. Details are available elsewhere. ${ }^{18}$ This two-factor method of analysis for the PAB scale has been used in previous studies. ${ }^{19}$

Patient beliefs about their general health were assessed using the Medical Outcomes Study ShortForm 36 (SF-36). This 36-item general quality-oflife measure has been extensively utilized and validated in medically ill outpatients. ${ }^{20}$ Scores are provided for physical function, role function-physical, role function-emotional, pain, social function, mental health, vitality, and general health.

\section{Other Patient Characteristics}

A structured psychiatric interview administered at baseline included mood, anxiety, and alcohol modules from the Prime-MD ${ }^{13}$ and the substance abuse and psychosis modules of the Structured Clinical Interview for Diagnosis. ${ }^{19}$ Only the diagnosis of dysthymia versus minor depression was used for the present analyses. To assess remission of depression, we used the interview-based 17-item HAM-D. ${ }^{14}$ The HAM-D was administered at baseline, 6 weeks, and 11 weeks by an independent rater who was blind to randomization. Scores ranged from 10 to 25 (mean $=13.73 \pm 2.92)$ in this study. The
HAM-D has been shown to have high reliability and validity in measuring depression. ${ }^{14}$ Remission was defined as having a HAM-D score of 6 or less at 11 weeks. Participants who attended at least four treatment sessions and had received a HAM-D score at 11 weeks by an independent rater were used in analyses. If the 11-week HAM-D score was missing, the 6-week score was carried forward. HAM-D scores were completed at 6 and 11 weeks by an independent rater blinded to group status.

Baseline psychological symptom severity was assessed with the 57-item version of the Hopkins Symptom Checklist. This self-report measure consists of five scales: depression, anxiety, interpersonal sensitivity, hostility, and somatization. ${ }^{20}$ The 20-item depression scale has been found to be a sensitive indicator of change in primary care samples. $^{21}$ Scores on this 20 -item scale ranged from 0.15 to 3.45 (mean $=1.5 \pm 0.68$ ). The NEO Neuroticism Scale consisted of 12 self-report items to assess neuroticism as a personality trait. ${ }^{22}$ In previous primary care studies, it was found to predict persistence of depressive symptoms, even after controlling for initial depression severity. ${ }^{23}$ The Duke Severity of Illness Index provided a quantification of the amount of medical comorbidity present in each patient as assessed by their physician. ${ }^{24}$ Scores were based on medical information abstracted from medical records by a physician.

\section{Statistical Analyses}

$t$-Tests and chi-square analyses with corrections for continuity were used to compare patients who were adherent to treatment visits with those who were not (0-3 treatment sessions compared with 4 or more sessions). $t$-Tests were used for the $\mathrm{PAB}$, SF-36, and Hopkins Symptom Checklist-57 subscales, as well as for the Duke medical illness severity scale and NEO Neuroticism Scale. Chisquare analyses with corrections for continuity were used for the discrete predictors of sex, age cohort, site, ethnicity (minority vs majority), marital status (married vs not married), employment status (full-time or part-time, retiredhomemaker, unemployed, or disabled), yearly income $(<\$ 20,000,>\$ 20,000)$, veteran status (patient of the Veterans Administration Hospital), psychiatric diagnosis (dysthymia, minor depression), and education ( $\leq 13$ years, $>13$ years). The same statistical tests were used to determine whether there were significant differences between 
Table 1. Groups Randomized to Paroxetine or Placebo with at Least Four Treatment Sessions.

\begin{tabular}{|c|c|c|c|c|c|c|}
\hline \multirow[b]{3}{*}{ Demographics } & \multicolumn{2}{|c|}{$\begin{array}{c}>4 \text { sessions }^{*} \\
\mathrm{n}=333\end{array}$} & \multicolumn{2}{|c|}{$\begin{array}{l}\text { Paroxetine } \\
\mathrm{n}=152\end{array}$} & \multicolumn{2}{|c|}{$\begin{array}{l}\text { Placebo } \\
\mathrm{n}=181\end{array}$} \\
\hline & No. & Percent & No. & Percent & No. & Percent \\
\hline & & & & & & \\
\hline Sex (female) & 172 & 52 & 73 & 48 & 99 & 55 \\
\hline Age cohort $>59$ y & 211 & 63 & 95 & 62 & 116 & 64 \\
\hline Ethnicity (majority) & 271 & 81 & 126 & 83 & 143 & 80 \\
\hline Married & 178 & 54 & 78 & 51 & 100 & 55 \\
\hline Employed & 124 & 37 & 58 & 38 & 66 & 36 \\
\hline Income, $y<\$ 20,000$ & 162 & 49 & 79 & 52 & 83 & 46 \\
\hline Veteran & 88 & 26 & 41 & 27 & 47 & 26 \\
\hline Minor depression & 159 & 48 & 71 & 47 & 88 & 49 \\
\hline \multirow{2}{*}{ Education $<13$ y } & 156 & 47 & 72 & 47 & 84 & 46 \\
\hline & Mean & $S D$ & Mean & $S D$ & Mean & $S D$ \\
\hline \multicolumn{7}{|l|}{ Patient beliefs (PAB) } \\
\hline Biological beliefs & 3.2 & 1.1 & 3.2 & 1.0 & 3.2 & 1.2 \\
\hline Psychological beliefs & 3.7 & 1.0 & 3.7 & 1.0 & 3.7 & 1.0 \\
\hline \multicolumn{7}{|l|}{ SCL scales } \\
\hline Depression & 1.5 & 0.6 & 1.5 & 0.6 & 1.4 & 0.7 \\
\hline Somatization & 1.0 & 0.7 & 1.1 & 0.7 & 1.0 & 0.7 \\
\hline Anxiety & 0.9 & 0.6 & 0.9 & 0.6 & 0.9 & 0.7 \\
\hline Hostility & 0.7 & 0.7 & 0.8 & 0.6 & 0.7 & 0.7 \\
\hline Interpersonal sensitivity & 1.0 & 0.7 & 1.0 & 0.7 & 1.0 & 0.7 \\
\hline \multicolumn{7}{|l|}{ SF-36 scales } \\
\hline General health & 53.3 & 22.5 & 52.2 & 23.0 & 54.2 & 22.1 \\
\hline Physical function & 60.3 & 28.8 & 58.9 & 28.4 & 61.4 & 29.3 \\
\hline Role physical & 38.3 & 40.1 & 38.3 & 40.9 & 38.2 & 39.6 \\
\hline Role emotional & 34.9 & 38.0 & 33.8 & 37.4 & 35.9 & 38.5 \\
\hline Pain & 52.2 & 24.4 & 52.4 & 24.4 & 52.0 & 24.4 \\
\hline Vitality & 32.8 & 19.4 & 32.2 & 19.4 & 33.2 & 19.5 \\
\hline Mental health & 53.8 & 17.2 & 52.8 & 17.0 & 54.7 & 17.3 \\
\hline Social function & 58.8 & 25.0 & 58.0 & 26.1 & 59.4 & 24.1 \\
\hline
\end{tabular}

*There were no significant differences on any variable between groups randomized to paroxetine and placebo.

$\mathrm{PAB}=$ Patient Attitudes and Beliefs Scale, SCL $=$ Hopkins Symptom Checklist-57 scales, SF-36 = Medical Outcomes Study Short-Form 36 Scale.

patients who received four treatments or more of paroxetine in comparison to those who received four treatments or more of the placebo.

Logistic regression modeling techniques were used to find the best set of predictors of remission. These procedures were performed separately for paroxetine responders and for placebo responders. (These issues have been explored separately for those participants assigned to the problem-solving therapy conditions.) ${ }^{18}$ Site (using Lebanon as a reference site) and age cohort were entered as predictors in each model regardless of statistical significance because of their use as design variables in the study, which were not randomly distributed between the treatment conditions. Potential predictor variables, including the belief measures and relevant clinical covariates, were entered into a model containing site and age cohort individually.

Predictors that were significant with $P$ values of .10 or less were considered as univariate potential predictors of recovery. These potential predictors were then entered into models after controlling for site and age cohort in a stepwise manner. Backward and forward stepwise procedures were used to determine the best fitting models. All models were tested for statistical outliers, but there were none. The final models for paroxetine and placebo response contained site, age cohort, and only predictors significant at a $P=.05$ or less. Although the models were built using all variables in their original continuous form, for ease of interpretation, continuous variables that were found to be significant predictors were dichotomized (using the median) to compute odds ratios for the tables.

\section{Results}

Statistical analyses showed that there was only one difference between patients who adhered to treatment for at least four treatment sessions and those who did not. Significantly more patients in the paroxetine group dropped out before completing four sessions compared with the placebo group, $\chi^{2}(1)=7.80, P<.005$. All other variables were 
Table 2. Possible Predictors of Response to Paroxetine $(n=152)$.

\begin{tabular}{|c|c|c|c|c|c|}
\hline \multirow[t]{2}{*}{ Variable } & \multicolumn{2}{|c|}{ Nonresponse } & \multicolumn{2}{|c|}{ Response } & \multirow[t]{2}{*}{ Wald's $t$ ( $P$ Value $)$} \\
\hline & No. & $\%$ & No. & $\%$ & \\
\hline \multicolumn{6}{|l|}{ Demographics } \\
\hline Sex (female) & 28 & 44 & 45 & 51 & 0.01 \\
\hline Older cohort $\geq 59 \mathrm{y}$ & 47 & 75 & 48 & 54 & $5.40(.02)$ \\
\hline Ethnicity (majority) & 46 & 73 & 80 & 90 & $5.59(.02)$ \\
\hline Married & 30 & 48 & 48 & 54 & 0.39 \\
\hline Employed & 16 & 25 & 42 & 47 & 2.37 \\
\hline Income, $y<\$ 20,000$ & 37 & 59 & 42 & 47 & 0.26 \\
\hline Veteran & 22 & 35 & 19 & 21 & 1.49 \\
\hline Dysthymia & 29 & 46 & 52 & 58 & $3.30(.08)$ \\
\hline Education $\leq 13 \mathrm{y}$ & 32 & 51 & 40 & 45 & 0.36 \\
\hline Site & & & & & $d f=3 ; 5.81(.12)$ \\
\hline Lebanon & 14 & 22 & 37 & 42 & \\
\hline Pittsburgh & 7 & 11 & 11 & 12 & \\
\hline San Antonio & 19 & 30 & 16 & 18 & \\
\hline \multirow[t]{2}{*}{ Seattle } & 23 & 36 & 25 & 28 & \\
\hline & Mean & $S D$ & Mean & $S D$ & \\
\hline \multicolumn{6}{|l|}{ Patient beliefs (PAB) } \\
\hline Biological belief & 3.6 & 0.9 & 3.0 & 1.0 & $11.74(.001)$ \\
\hline Psychological belief & 3.5 & 1.0 & 3.6 & 0.8 & 0.01 \\
\hline \multicolumn{6}{|l|}{ Clinical } \\
\hline Duke Severity of Illness & 25.3 & 14.6 & 19.6 & 13.2 & 1.51 \\
\hline NEO-Neuroticism Scale & 3.0 & 0.7 & 3.1 & 0.6 & 0.01 \\
\hline \multicolumn{6}{|l|}{ SCL scales } \\
\hline Depression & 1.6 & 0.6 & 1.5 & 0.6 & 0.01 \\
\hline Somatization & 1.3 & 0.6 & 0.9 & 0.7 & $2.46(.12)$ \\
\hline Anxiety & 0.9 & 0.6 & 0.8 & 0.6 & $7.34(.007)$ \\
\hline Hostility & 0.7 & 0.6 & 0.8 & 0.6 & $0.01,2.68(.10)$ \\
\hline Interpersonal sensitivity & 1.1 & 0.7 & 1.0 & 0.7 & $4.32(.04)$ \\
\hline \multicolumn{6}{|l|}{ SF-36 scales } \\
\hline General health & 43.4 & 21.4 & 58.5 & 22.2 & $12.04(.001)$ \\
\hline Physical function & 51.6 & 28.9 & 64.0 & 26.9 & $4.55(.03)$ \\
\hline Role physical & 24.6 & 33.1 & 47.8 & 43.2 & $9.05(.003)$ \\
\hline Role emotional & 30.6 & 37.2 & 36.0 & 37.7 & 0.57 \\
\hline Pain & 48.8 & 20.3 & 55.0 & 26.7 & 1.41 \\
\hline Vitality & 30.2 & 19.1 & 33.7 & 19.5 & $3.58(.06)$ \\
\hline Mental health & 53.2 & 16.3 & 52.6 & 17.6 & 1.25 \\
\hline Social functioning & 53.8 & 26.2 & 61.0 & 25.8 & $4.23(.04)$ \\
\hline
\end{tabular}

$\mathrm{PAB}=$ Patient Attitudes and Beliefs Scale, SCL $=$ Hopkins Symptom Checklist-57 scales, SF-36 = Medical Outcomes Study Short-Form 36 Scale.

similar between the two groups. Among patients who adhered to at least four treatment sessions, there were no significant differences between those randomly assigned to paroxetine and those randomized to placebo. Demographic and clinical characteristics of this sample are displayed in Table 1.

Table 2 shows the predictors stratified by patient response to paroxetine. The table also shows the univariate significance of the predictors in a model containing only site and age cohort. Patients responding to paroxetine had significantly lower scores on the biological belief scale. Patients who responded to paroxetine also were more likely to be in the younger cohort, be white, and have dysthymia as opposed to minor depression. Patients who responded to paroxetine also had lower levels of baseline depression, somatization, anxiety, and in- terpersonal sensitivity symptoms on the Hopkins Symptom Checklist-57 than patients who did not respond to the medication. In addition, patients who responded to paroxetine had better general health perceptions, physical health, vitality, social functioning, and fewer limitations in physical functioning than patients who did not respond to the medication. The logistic regression model included site, age cohort, and the significant predictors from those that were significant in the univariate analyses.

The final multivariate model for remission on paroxetine can be seen in Table 3. Results of the logistic regression showed that patients who responded were more likely to be younger, dysthymic, have better general health perceptions and less biological beliefs than patients who did not respond to paroxetine. 
Table 3. Multivariate Model for Remission on Paroxetine.

\begin{tabular}{|c|c|c|c|c|c|}
\hline Predictors & $\beta$ & $d f$ & Wald's $t$ & Odds Ratio & $95 \% \mathrm{CI}$ \\
\hline Younger age cohort $(<59$ y) & 0.99 & 1 & $4.10^{*}$ & 2.68 & $1.03-6.98$ \\
\hline $\begin{array}{l}\text { Site } \\
\text { Lebanon (ref) } \\
\text { Pittsburgh } \\
\text { San Antonio } \\
\text { Seattle }\end{array}$ & $\begin{array}{r}\overline{0.19} \\
0.61 \\
-0.95\end{array}$ & $\begin{array}{l}3 \\
1 \\
1 \\
1\end{array}$ & $\begin{array}{l}5.21 \\
0.07 \\
1.18 \\
3.77^{*}\end{array}$ & $\begin{array}{l}\overline{1.20} \\
0.54 \\
0.39\end{array}$ & $\begin{array}{c}- \\
0.31-4.63 \\
0.18-1.64 \\
0.15-1.00\end{array}$ \\
\hline Biological belief (low) & 1.26 & 1 & $9.48^{\dagger}$ & 3.51 & $1.58-7.80$ \\
\hline Dysthymia & 0.99 & 1 & $5.82^{\dagger}$ & 2.69 & $1.20-6.02$ \\
\hline SF-36 general health (high) & 1.32 & 1 & $11.42^{\ddagger}$ & 3.73 & $1.74-8.00$ \\
\hline
\end{tabular}

$\mathrm{CI}=$ confidence interval, SF-36 $=$ Medical Outcomes Study Short-Form 36 Scale

${ }^{*} P<.05$.

${ }^{\dagger} P<.01$.

${ }^{\ddagger} P<.001$.

Table 4 shows the possible predictors stratified by patients who responded to the placebo. The table also shows the univariate significance of the predictors in a model containing only site and age cohort. Patients responding to placebo also had significantly lower scores on the biological belief scale. In addition, patients who responded to the placebo were more likely to be women, married, veterans, and have more education than patients who did not respond to the placebo. Patients who responded to the placebo had a lower NEOneuroticism score, and also had lower scores on all the Hopkins Symptom Checklist-57 scales of baseline depression, somatization, anxiety, hostility, and interpersonal sensitivity symptoms than patients who did not respond to the placebo. In addition, patients who responded to the placebo had better scores on all the SF-36 subscales (with the exception of physical functioning) than those who did not respond to the placebo. The logistic regression model included site, age cohort, and the significant predictors from the univariate analyses.

The final multivariate model for remission on placebo can be seen in Table 5. Results of the logistic regression showed that patients who responded to the placebo were more likely to be women and have lower baseline depression symptom severity than patients who did not respond to paroxetine. No belief variables remained significant in the multivariate model.

\section{Discussion}

Our analysis suggests that patient beliefs about their health and depression add to depression type and age to predict responsiveness to antidepressant medications among primary care patients with minor depression and dysthymia. Contrary to our hypothesis, no beliefs were found to be predictive of adherence to at least 8 weeks (four visits) of medication treatment. Also contrary to hypothesis, a lower endorsement of biological beliefs predicted response to paroxetine. Significant multivariate predictors of remission for those receiving at least 4 weeks of paroxetine included age, dysthymia, less belief in a biological model of depression, and greater self-rated health. Eighty-four percent of patients were correctly classified as responders or nonresponders by this model. Significant multivariate predictors of remission for those receiving at least 4 weeks of placebo included only female sex and lower initial depressive symptom severity. A conservative interpretation of this data is that patients with minor depression and dysthymia do not need to believe that their illness is biological to respond to biological treatment for depression, ie, antidepressants.

Medical comorbidity is associated with major and minor depression in primary and specialty medical care. ${ }^{21}$ This comorbidity has been previously reported to be associated with poorer major depression outcomes in primary care. A number of factors could contribute to this outcome, including decreased discussion and recognition of depression and initiation of treatment in the presence of medical comorbidity. ${ }^{24}$ Chronic medical illness might impede remission and promote relapse of depression, especially when such illness is associated with physical disability. ${ }^{22}$ In our study, both objective health (physician-rated comorbidity on the Duke Severity of Illness Scale) and subjective health 
Table 4. Possible Predictors of Response for Nonresponders $(n=94,52 \%)$ and Responders $(n=86,49 \%)$ Receiving Placebo $(\mathrm{n}=180)$.

\begin{tabular}{|c|c|c|c|c|c|}
\hline \multirow[t]{2}{*}{ Variable } & \multicolumn{2}{|c|}{ Nonresponders } & \multicolumn{2}{|c|}{ Responders } & \multirow[t]{2}{*}{ Wald's $t$ ( $P$ Value $)$} \\
\hline & No. & $\%$ & No. & $\%$ & \\
\hline \multicolumn{6}{|l|}{ Demographics } \\
\hline Sex (female) & 45 & 48 & 54 & 63 & $4.42(.04)$ \\
\hline Age cohort > 59 y & 64 & 68 & 52 & 61 & 0.95 \\
\hline Ethnicity (majority) & 74 & 79 & 70 & 81 & 4.94 \\
\hline Married & 44 & 47 & 55 & 64 & $4.72(.03)$ \\
\hline Employed & 33 & 35 & 32 & 37 & 0.08 \\
\hline Income, y $<\$ 20,000$ & 42 & 45 & 41 & 48 & 0.29 \\
\hline Veteran & 29 & 31 & 18 & 21 & $3.24(.07)$ \\
\hline Dysthymia & 54 & 57 & 38 & 44 & 2.04 \\
\hline Education $<13 \mathrm{y}$ & 49 & 52 & 35 & 41 & $2.70(.10)$ \\
\hline Sites & & & & & 4.94 \\
\hline Lebanon & 27 & 29 & 31 & 36 & \\
\hline Pittsburgh & 11 & 12 & 17 & 20 & \\
\hline San Antonio & 25 & 26 & 14 & 16 & \\
\hline \multirow[t]{2}{*}{ Seattle } & 31 & 33 & 24 & 28 & \\
\hline & Mean & $S D$ & Mean & $S D$ & \\
\hline \multicolumn{6}{|l|}{ Patient beliefs } \\
\hline Biological beliefs & 3.4 & 1.1 & 3.0 & 1.2 & $4.88(.03)$ \\
\hline Psychological beliefs & 3.7 & 0.9 & 3.4 & 1.0 & $2.74(.10)$ \\
\hline \multicolumn{6}{|l|}{ Clinical } \\
\hline Duke Severity of Illness & 21.7 & 13.8 & 19.4 & 13.2 & 0.33 \\
\hline NEO_Neuroticism Scale & 3.1 & 0.7 & 2.9 & 0.6 & $5.04(.02)$ \\
\hline \multicolumn{6}{|l|}{ SCL scales } \\
\hline Depression & 1.6 & 0.6 & 1.3 & 0.6 & $8.04(.005)$ \\
\hline Somatization & 1.1 & 0.8 & 0.9 & 0.6 & $3.73(.05)$ \\
\hline Anxiety & 1.0 & 0.7 & 0.8 & 0.6 & $8.04(.005)$ \\
\hline Hostility & 0.8 & 0.8 & 0.6 & 0.6 & $2.52(.10)$ \\
\hline Interpersonal sensitivity & 1.1 & 0.8 & 0.8 & 0.7 & $8.83(.003)$ \\
\hline \multicolumn{6}{|l|}{ SF-36 } \\
\hline General health & 50.4 & 22.9 & 58.2 & 20.6 & $5.04(.02)$ \\
\hline Physical function & 57.0 & 30.7 & 66.0 & 27.0 & 2.38 \\
\hline Role physical & 32.0 & 35.8 & 44.3 & 42.4 & $3.64(.06)$ \\
\hline Role emotional & 30.5 & 37.3 & 42.3 & 39.1 & $3.72(.05)$ \\
\hline Pain & 47.0 & 24.9 & 57.0 & 22.5 & $7.42(.006)$ \\
\hline Vitality & 30.1 & 19.2 & 36.6 & 19.5 & $5.24(.02)$ \\
\hline Mental health & 52.6 & 16.3 & 57.0 & 18.3 & $4.64(.03)$ \\
\hline Social function & 54.7 & 24.7 & 64.6 & 22.7 & $6.75(.009)$ \\
\hline
\end{tabular}

SCL $=$ Hopkins Symptom Checklist-57 scales, SF-36 = Medical Outcomes Study Short-Form 36 scale.

(overall perceived health on the SF-36) were univariate predictors of depression remission on paroxetine. In the multivariate model, only subjective health remained in the model. Other SF-36 scales were also univariate predictors (physical function, role physical function, and social function), but these did not remain in the multivariate model. This finding of predictive power for subjective

Table 5. Multivariate Model Predicting Remission on Placebo.

\begin{tabular}{|c|c|c|c|c|c|}
\hline Predictors & $\beta$ & $d f$ & Wald's $t$ & Odds Ratio & $95 \% \mathrm{CI}$ \\
\hline Younger age cohort $(>59$ y) & 0.51 & 1 & 1.45 & 1.66 & $0.73-3.80$ \\
\hline $\begin{array}{l}\text { Site } \\
\text { Lebanon (reference) } \\
\text { Pittsburgh } \\
\text { San Antonio } \\
\text { Seattle }\end{array}$ & $\begin{array}{r}\overline{0.81} \\
-0.22 \\
-0.33\end{array}$ & $\begin{array}{l}3 \\
1 \\
1 \\
1\end{array}$ & $\begin{array}{l}5.15 \\
1.99 \\
0.18 \\
0.68\end{array}$ & $\begin{array}{l}-\overline{2} \\
0.80 \\
0.72\end{array}$ & $\begin{array}{l}- \\
0.73-6.98 \\
0.29-2.23 \\
0.32-1.58\end{array}$ \\
\hline Sex, female & 0.77 & 1 & $5.09^{*}$ & 2.18 & $1.11-4.27$ \\
\hline Baseline depression severity-low & 0.99 & 1 & $8.61^{\dagger}$ & 2.70 & $1.39-5.24$ \\
\hline
\end{tabular}

${ }^{*} P<.05$.

${ }^{\dagger} P<.01$ 
health is consistent with epidemiologic research showing that subjective health predicts mortality even after controlling for objective health. ${ }^{23}$ Our study is the first to point toward subjective health as a predictor of antidepressant response in less severe forms of depression.

The hardest finding to explain from this study is that less belief in a biological model of depression predicted better response to a biological treatment for depression, paroxetine. Four items make up the biological subscale of the Patient Attitudes and Beliefs Scale: (1) "an imbalance of certain substances in my brain is a cause of my problems," (2) "an illness which affects me emotionally rather than physically is a cause of my problems," (3) "an upset in brain chemistry which comes and goes is a cause of my problems," and (4) "a medical illness which runs in my family (like diabetes) is a cause of my problem." These items formed a single factor in the original study with this scale and in our current study. One reason why endorsement of these beliefs might be associated with poor medication response is that they imply passive or fatalistic attitude toward depression. These beliefs were also a univariate (but not multivariate) predictor of nonresponse to placebo, which implies that the predictive power of these beliefs is not limited to those on active pharmacotherapy. It is not clear whether this finding applies only to those with less severe forms of depression or only to those seen in primary care settings.

These biological beliefs might also function as a proxy for factors known to predict poor response to depression treatment. The biological beliefs scale was positively correlated with neuroticism (Pearson $r=0.27, P<.01)$ and baseline depression severity on the Hopkins Symptom Checklist-20 (Pearson $r=.23, P<.01)$. Neuroticism and severity of depression have been strong predictors of nonresponse to depression treatment in primary care. ${ }^{25}$ It was also negatively correlated with education (Pearson $r=-.23, P<.01$ ). Higher education is associated in past studies with improved prognosis for depression and chronic medical illnesses. ${ }^{26}$ Taken individually, these correlations are not strong, but taken as a group, they begin to explain why the group that endorsed the biological beliefs was less likely to respond to paroxetine, and to a lesser extent, placebo.

A very important limitation of studies of patient beliefs before the initiation of treatment is that the education and negotiation involved in treatment planning and actual experience with treatment can change patient beliefs. Many patients have misperceptions about medications and psychotherapy that can be corrected by family physicians. ${ }^{27}$ There is also evidence that experience with depression treatment can change patients' beliefs about the helpfulness of various treatments. In a population survey of 3,109 Australian adults about the helpfulness of treatments for depression, those who had sought help for depression were less likely to believe in the helpfulness of lifestyle interventions and more likely to believe in the helpfulness of medical interventions, such as antidepressants. ${ }^{28} \mathrm{~A}$ follow-up survey of 422 of these adults with depressive symptoms showed that belief in the helpfulness of a depression intervention predicted use of that intervention only for antidepressants. ${ }^{29}$ A separate study found that endorsement of interpersonal difficulties as a cause for depression was associated with poorer adherence to medication. ${ }^{30}$

Surveys of the British public ${ }^{31}$ and American primary care patients with depression ${ }^{32}$ have also shown a preference for counseling rather than antidepressants. Yet two recent randomized trials have shown no better responsiveness to treatment among those who were randomized to their preferred treatment. ${ }^{33}$ We did not assess treatment preference in this study, but we did show an interesting mismatch between beliefs about cause of depression and response to treatment. Clearly our results indicate that patients need not believe in a biological model of depression before seeing their physician to show response to an antidepressant. Interestingly, belief in a biological model also did not predict adherence to the antidepressant or placebo.

Our study suggests that patient beliefs might add to clinical characteristics in predicting which patients with less severe forms of depression are more likely to respond to an adequate course of a selective serotonin reuptake inhibitor. Younger patients who see themselves as generally healthy and perceive their depression in less biological terms appear more likely to respond. Less severely depressed women are more likely to respond to placebo. Because this outcome could be due to the greater likelihood of spontaneous remission in this group, these patients might be scheduled for a return appointment after 1 or 2 months of watchful 
waiting rather than being placed immediately on active treatment.

\section{References}

1. Wells KB, Stewart A, Hays RD, et al. The functioning and well-being of depressed patients. Results from the Medical Outcomes Study. JAMA 1989;262: 914-9.

2. Katon W, Von Korff M, Lin E, et al. Distressed high utilizers of medical care. Gen Hosp Psychiatry 1990; 12:355-62.

3. Hybels CF, Blazer DG, Pieper CF. Toward a threshold for subthreshold depression: an analysis of correlates of depression by severity of symptoms using data from an elderly community sample. Gerontologist 2001;41:357-65.

4. Main DS, Lutz LJ, Barrett JE, Matthew J, Miller RS. The role of primary care clinician attitudes, beliefs, and training in the diagnosis and treatment of depression. A report from the Ambulatory Sentinel Practice Network Inc. Arch Fam Med 1993; 2:1061-6.

5. Kuyken W, Brewin CR, Power MJ, Furnham A. Causal beliefs about depression in depressed patients, clinical psychologists and lay persons. $\mathrm{Br} \mathrm{J}$ Med Psychol 1992;65(Pt 3):257-68.

6. Steiner M, Bell B, Browne G, et al. Prevalence of dysthymic disorder in primary care. J Affect Disord 1999;54:303-8.

7. Kroenke K, Spitzer RL, Williams JB, et al. Physical symptoms in primary care: Predictors of psychiatric disorders and functional impairment. Arch Fam Med 1994;3:774-9.

8. Brown C, Schulberg HC, Madonia MJ, Shear MK, Houck PR. Treatment outcomes for primary care patients with major depression and lifetime anxiety disorders. Am J Psychiatry 1996;153:1293-300.

9. Beck DA, Koenig HG. Minor depression: a review of the literature. Int J Psychiatry Med 1996;26:177209.

10. Pincus HA, Davis WW, McQueen LE. 'Subthreshold' mental disorders. A review and synthesis of studies on minor depression and other 'brand names'. Br J Psychiatry 1999;174:288-96.

11. Kessler RC, Zhao S, Blazer DG, Swartz M. Prevalence, correlates, and course of minor depression and major depression in the National Comorbidity Survey. J Affect Disord 1997;45:19-30.

12. Lyness JM, King DA, Cox C, Yoediono Z, Caine ED. The importance of subsyndromal depression in older primary care patients: prevalence and associated functional disability. J Am Geriatr Soc 1999;47: 647-52.

13. Szegedi A, Wetzel H, Angersbach D, Philipp M, Benkert O. Response to treatment in minor and major depression: results of a double-blind compar- ative study with paroxetine and maprotiline. J Affect Disord 1997;45:167-78.

14. Rapaport MH, Judd LL. Minor depressive disorder and subsyndromal depressive symptoms: functional impairment and response to treatment. J Affect Disord 1998;48:227-32.

15. Williams JW Jr, Barrett J, Oxman T, et al. Treatment of dysthymia and minor depression in primary care: a randomized controlled trial in older adults. JAMA 2000;284:1519-26.

16. Barrett JE, Williams JW Jr, Oxman TE, et al. Treatment of dysthymia and minor depression in primary care: a randomized trial in patients aged 18 to 59 years. J Fam Pract 2001;50:405-12.

17. Elkin I, Shea MT, Watkins JT, et al. National Institute of Mental Health Treatment of Depression Collaborative Research Program. General effectiveness of treatments. Arch Gen Psychiatry 1989;46: 971-82.

18. Hegel MT, Barrett JE, Cornell JE, Oxman TE. Predictors of response to problem solving treatment of depression in primary care. Behav Ther 2002;33: 511-27.

19. Spanier C, Frank E, McEachran AB, Grochocinski VJ, Kupfer DJ. The prophylaxis of depressive episodes in recurrent depression following discontinuation of drug therapy: integrating psychological and biological factors. Psychol Med 1996;26:461-75.

20. Ware JE Jr, Sherbourne CD. The MOS 36-item short-form health survey (SF-36). I. Conceptual framework and item selection. Med Care 1992;30: $473-83$.

21. Koenig HG. Differences in psychosocial and health correlates of major and minor depression in medically ill older adults. J Am Geriatr Soc 1997;45: 1487-95.

22. Lenze EJ, Rogers JC, Martire LM, et al. The association of late-life depression and anxiety with physical disability: a review of the literature and prospectus for future research. Am J Geriatr Psychiatry 2001;9:113-35.

23. Idler EL, Benyamini Y. Self-rated health and mortality: a review of twenty-seven community studies. J Health Soc Behav 1997;38:21-37.

24. Rost K, Nutting P, Smith J, Coyne JC, CooperPatrick L, Rubenstein L. The role of competing demands in the treatment provided primary care patients with major depression. Arch Fam Med 2000; 9:150-4.

25. Katon W, Lin E, von Korff M, et al. The predictors of persistence of depression in primary care. J Affect Disord 1994;31:81-90.

26. Miech RA, Shanahan MJ. Socioeconomic status and depression over the life course. J Health Soc Behav 2000;41:162-76.

27. Lin EH, Von Korff M, Katon W, et al. The role of the primary care physician in patients' adherence to antidepressant therapy. Med Care 1995;33:67-74. 
28. Jorm AF, Christensen H, Medway J, Korten AE, Jacomb PA, Rodgers B. Public belief systems about the helpfulness of interventions for depression: associations with history of depression and professional help-seeking. Soc Psychiatry Psychiatr Epidemiol 2000;35:211-9.

29. Jorm AF, Medway J, Christensen H, Korten AE, Jacomb PA, Rodgers B. Public beliefs about the helpfulness of interventions for depression: effects on actions taken when experiencing anxiety and depression symptoms. Aust N Z J Psychiatry 2000;34: 619-26.

30. Brown C, Dunbar-Jacob J, Palenchar DR, et al. Primary care patients' personal illness models for depression: a preliminary investigation. Fam Pract 2001;18:314-20.

31. Priest RG, Vize C, Roberts A, Roberts M, Tylee A. Lay people's attitudes to treatment of depression: results of opinion poll for Defeat Depression Campaign just before its launch. BMJ 1996;313:858-9.

32. Dwight-Johnson M, Sherbourne CD, Liao D, Wells $\mathrm{KB}$. Treatment preferences among depressed primary care patients. J Gen Intern Med 2000;15: $527-34$.

33. Thornett A. Assessing the effect of patient and prescriber preference in trials of treatment of depression in general practice. Med Sci Monit 2001;7:1086-91. 